\title{
A Eficiência do Modelo de Elton-Gruber na Formação de Carteira de Ações no Brasil
}

\author{
The Efficiency Elton-Gruber's Model in the structure of the Portfolio Shares in \\ Brazil
}

\author{
Adriano Leal Bruni \\ Doutor em Administração pela FEA-USP \\ Professor Titular da UFBA \\ Roberto Brazileiro Paixão \\ Mestre em Administração pela UNIFACS \\ Professor Assistente da UFBA
}

\author{
Utilan da Silva Ramos Coroa \\ Universidade Federal da Bahia \\ César Valentim de Oliveira Carvalho Júnior \\ Doutorando em Controladoria e Contabilidade pela \\ USP \\ Professor AssiStente da UFBA
}

\section{Resumo}

A administração de carteiras de ativos financeiros vem procurando apresentar mecanismos para a obtenção de uma relação ótima entre retorno e risco. Inúmeros estudos vêm contribuindo de forma significante para a eficiência e prática destas técnicas. Este trabalho objetivou analisar a possibilidade de se obter desempenhos superiores nas estratégias de investimentos mediante a utilização do modelo de Elton-Gruber, no Brasil, no período de janeiro de 2000 a setembro de 2006, considerando-se a formação de preços informacionalmente eficiente. Para avaliar o mercado informacional de preços analisou-se inicialmente se os retornos das ações selecionadas seguiam rumo aleatório. Foi aplicado o Teste de Corridas (runs test) e o teste de Durbin-Watson. Este trabalho conclui que, a aplicação deste método, devido às suas características, pode proporcionar retornos maiores que aplicações no Ibovespa, com menores riscos, considerando-se o mercado informacional eficiente na forma fraca.

Palavras-Chave: Administração de Investimentos, Elton-Gruber, Mercado de Capitais, Retorno, Risco.

\begin{abstract}
The portfolio administration of financial assets is trying to present mechanisms to obtain the better connection between return and risk of assets. Innumerable studies are contributing efficiently to the significance and practice of this technique. The purpose of this work was to investigate the possibility to obtain superior performances in the strategies of investments by the use of Elton-Gruber method, in Brazil, during the period of Jan'00 to Sept'06, considering efficient the informational market of prices formation. To evaluate the market's efficiency, initially the random walk of the stock's returns was analyzed. Were applied the Run Test and Durbin-Watson's test. This work concluded that, the application of this method, due to their characteristics, can provide superior returns than investments in Ibovespa, with smaller risks, considering efficient the informational market in the weak form.
\end{abstract}

Keywords: Investments Administration, Elton-Gruber, Capitals Market, Return, Risk.

\section{INTRODUÇÃO}

A administração de carteiras de ativos financeiros vem procurando apresentar mecanismos para a obtenção de uma relação ótima entre retorno e risco. Dentre os mecanismos utilizados para a otimização encontra-se o modelo de média-variância de 
Markowitz (1952) que contribuiu para o avanço dos modelos de determinação da taxa esperada de retorno dos ativos, através do desenvolvimento da Moderna Teoria de Carteiras, segundo a qual os investidores tomam decisões de investimento considerando dois parâmetros das distribuições de probabilidade dos diversos ativos da economia: a média e a variância, preferindo sempre mais retorno e menos risco. O risco seria quantificado pela variância dos retornos dos ativos de um mercado, permitindo ao investidor escolher de um conjunto de ativos o de maior retorno a partir de determinado risco aceitável, ou obter um menor risco dado um retorno esperado para o portifólio a ser formado.Carteiras otimizadas seriam formadas, simultaneamente, por máximo retorno e mínimo risco.

Um procedimento para a otimização de carteiras pode ser apresentado por meio do modelo de de Elton-Gruber (1995), que utiliza como parâmetro de seleção das ações o Índice de Atratividade. Esse índice está diretamente associado com o seu retorno excessivo (retorno esperado de cada ação menos ativo livre de risco) em relação ao seu risco não diversificável. Markowitz (1952) afirma que um bom portfólio de ativos é mais que uma grande lista de boas ações e títulos de dívida. É um conjunto balanceado que fornece ao investidor proteções e oportunidades em um conjunto amplo de situações.

O objetivo geral do presente estudo consistiu em investigar se a construção de carteiras de ações pelo método de Elton-Gruber possibilitaria a obtenção de desempenhos superiores em relação ao índice de mercado brasileiro, ou seja, aumento de retorno e diminuição do risco. Outros objetivos específicos consistiram em: verificar se os retornos das vinte ações mais líquidas da Bovespa, no período deste estudo estão condizentes com a hipótese de eficiência da formação de preços do mercado; analisar o comportamento das carteiras de ações com a aplicação do método de Elton-Gruber no Brasil no período de janeiro de 2000 a setembro de 2006, em relação ao Ibovespa.

\section{FUNDAMENTAÇÃO TEÓRICA}

Nos modelos quantitativos de investimentos freqüentemente é utilizado a análise da média e variância de uma carteira de investimento. Conforme Elton et al. (2004, p. 65), o retorno de uma carteira de ativos é simplesmente uma média ponderada dos retornos dos ativos individuais. Quando um investidor aplica certa quantia de recursos financeiros em um ativo durante determinado período de tempo, ele tem uma expectativa de retorno que é denominada média ou retorno médio do período.

Porém, o risco mensurado a partir de um retorno médio de um ativo pode ser quantificado pela variação dos retornos deste ativo com relação ao retorno esperado que é a média dos possíveis retornos de um ativo financeiro multiplicado pela probabilidade de ocorrência destes retornos. Então, na escolha de alternativas de investimentos, dentre outras possibilidades, o investidor deverá observar o retorno e risco associado à oportunidade de investimento. Contudo a análise e as técnicas desenvolvidas para administração de carteira observarão, além do conceito amplo de risco e retorno, outras variáveis, outros aspectos com o objetivo primordial de maximizar o seu retorno e minimizar o seu risco.

Markowitz (1952) publicou um trabalho intitulado Portfolio Selection no qual sinalizava para a prática de diversificação de carteiras de ações e mostrava como um investidor poderia reduzir o impacto das oscilações de um retorno em uma carteira de títulos, escolhendo ações que não variassem do mesmo modo em conjunto. Fez a introdução do conceito de carteira eficiente e demonstrou os princípios básicos para a composição dessa carteira. 
Segundo o autor, as duas únicas variáveis que interessa ao investidor são o retorno esperado e o risco, explicitado pela variância desses retornos, assumindo que os investidores são avessos ao risco.

Com relação ao retorno esperado da carteira a fórmula que permite o seu cálculo é simplesmente a média ponderada do retorno esperado de cada título:

$$
E\left(R_{p}\right)=X_{1} E\left(R_{1}\right)+X_{2} E\left(R_{2}\right)+\ldots+X_{N} E\left(R_{N}\right)
$$

Onde $\mathrm{X}_{1}, \mathrm{X}_{2}, \mathrm{X}_{\mathrm{n}}$ representam o percentual dos recursos investidos em cada um dos títulos 1,2 , n, que compõem a carteira.

Para o cálculo do risco da carteira utiliza-se o coeficiente de correlação ou a covariância com o objetivo de relacionar os retornos dos títulos que irão compor a carteira, dois a dois. As fórmulas utilizadas para o cálculo da covariância e do coeficiente de correlação entre os retornos de dois títulos são:

$$
\sigma_{A B}=\frac{\Sigma\left(R_{A}-\bar{R}_{A}\right) \cdot\left(R_{B}-\bar{R}_{B}\right)}{N} \quad \rho_{A B}=\frac{\sum\left(R_{A}-\bar{R}_{A}\right) \cdot\left(R_{B}-\bar{R}_{B}\right) \div N}{\sqrt{\frac{\sum\left(R_{A}-\bar{R}_{A}\right)^{2}}{N} \times \sqrt{\frac{\sum\left(R_{B}-\bar{R}_{B}\right)^{2}}{N}}}}
$$

Onde: $\sigma_{A B}=$ covariância entre dois títulos $(\mathrm{A}$ e $\mathrm{B}) ; R_{A}=$ retorno do título $\mathrm{A}$ em determinado período; $R_{A}=$ retorno esperado do título $\mathrm{A} ; R_{B}=$ retorno do título $\mathrm{B}$ em determinado período; $R_{B}^{-}=$retorno esperado do título B; $N=$ número de observações; $\rho_{A B}$ $=$ coeficiente de correlação linear entre dois títulos (A e B).

$\mathrm{O}$ risco de uma carteira para mais de duas variáveis fica assim definido: $\sigma_{p}^{2}=X_{1}^{2} \sigma_{1}^{2}+X_{2}^{2} \sigma_{2}^{2}+X_{3}^{2} \sigma_{3}^{2}+\ldots+2 X_{1} X_{2} \sigma_{12}+2 X_{1} X_{3} \sigma_{13}$. Com base nessa expressão verifica-se que, quanto menor a covariância entre os retornos de duas ações menor o risco da carteira. Caso a covariância seja negativa o risco da carteira será menor do que a média ponderada do risco de cada um dos títulos que a compõem. Essa é a chave da diversificação eficiente proposta por Markowitz.

Segundo Tosta de Sá (1999), os estudos de Markowitz estão fundamentados nas seguintes premissas: (a) a análise é efetuada considerando sempre as expectativas geradas para um período adiante (seja um mês, um ano, um semestre, ou qualquer outro período previamente definido); (b) todos os investidores buscam maximizar a utilidade esperada para o período do investimento e apresentam utilidade marginal decrescente; (c) todos os investidores elaboram suas projeções de rentabilidade para os ativos a partir da distribuição de probabilidades para as várias taxas de retorno que podem ser alcançadas no período do investimento; (d) os investidores associam risco à variabilidade das taxas de retorno dos ativos em análise; (e) os investidores baseiam suas decisões somente em termos do retorno esperado e do risco do investimento. A liquidez está embutida no risco; (f) para qualquer nível de risco, os investidores preferem maiores retornos a menores retornos, ou ainda, para qualquer nível de retorno esperado, os investidores preferem menos riscos a mais riscos.

Considerando um portfolio com dois ativos, o retorno é a média ponderada dos retornos individuais de cada ativo e risco, a variância, na qual é representada pela soma das variâncias individuais dos ativos multiplicados pelo quadrado dos seus percentuais mais a covariância que é a medida de como os retornos dos ativos variam em conjunto.

A variância da carteira depende da covariância entre os pares de ativos, a qual por sua vez depende da correlação entre os ativos. Então, quando dois ou mais ativos pouco 
relacionados compõem uma carteira de investimento, consegue-se um risco menor que a média ponderada dos riscos individuais, auferindo um risco menor que o do ativo de menor risco com um retorno maior que o deste ativo.

Pode-se perceber que quanto maior o número de ativos em uma carteira, o risco individual de cada ativo dado pela variância perde importância e o que passa a ter importância é a inter-relação dos ativos, dado pela covariância, que é o risco sistêmico, conjuntural, comum a todos os ativos do mesmo mercado. Em outras palavras, a medida que se aumenta a diversificação de uma carteira, os riscos individuais perdem importância frente a covariância média dos retornos. O que modifica não é o valor das variâncias dos ativos, mas a importância relativa deles.

O risco em Finanças é dividido em diversificável que está relacionado com o ativo ou negócio e o não diversificável ou de mercado que é exógeno ao ativo ou negócio.

Para um investidor com visão generalista, um modo mais eficiente de obter redução dos riscos é através da aplicação da carteira de ativos.

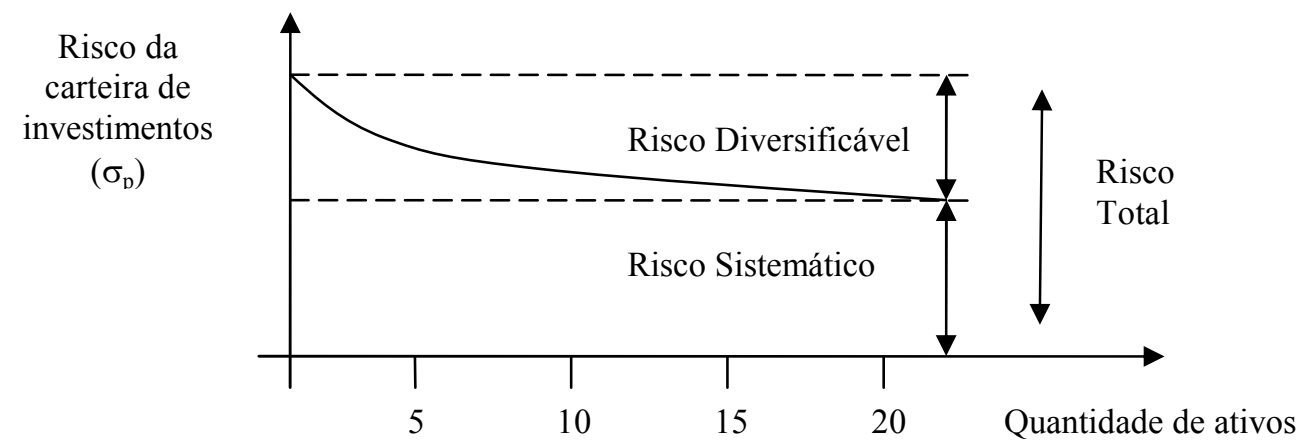

Figura 1. A redução do risco pela diversificação.

Fonte: Assaf Neto (2001, p. 273).

Os investidores, objetivando reduzir o risco total das suas aplicações deveriam manter carteiras diversificadas em vez de concentradas em poucos ativos. $\mathrm{O}$ grau de redução do risco vai depender de quão negativamente correlacionados são os ativos da carteira. Quanto menor o nível das correlações, maiores as reduções obtidas. Entretanto, existem os riscos que não podem ser reduzidos pela diversificação, e estes são chamados de ricos sistêmicos e afetam todos os ativos de mercado. Os valores dos títulos de empresas locais tenderiam a variar em conjunto porque seriam afetados pelos mesmos fatores econômicos nacionais, tais como oscilações da oferta de moeda, de taxa de juros, mudança de política fiscal e variações da taxa de crescimento da economia.

Admitindo-se $\mathrm{n}$ ativos, as possíveis combinações infinitas de carteiras resultariam em uma junção delimitada por uma hipérbole. Dessa maneira, tem-se um conjunto de pontos otimizados na relação risco retorno, denominado fronteira eficiente. 


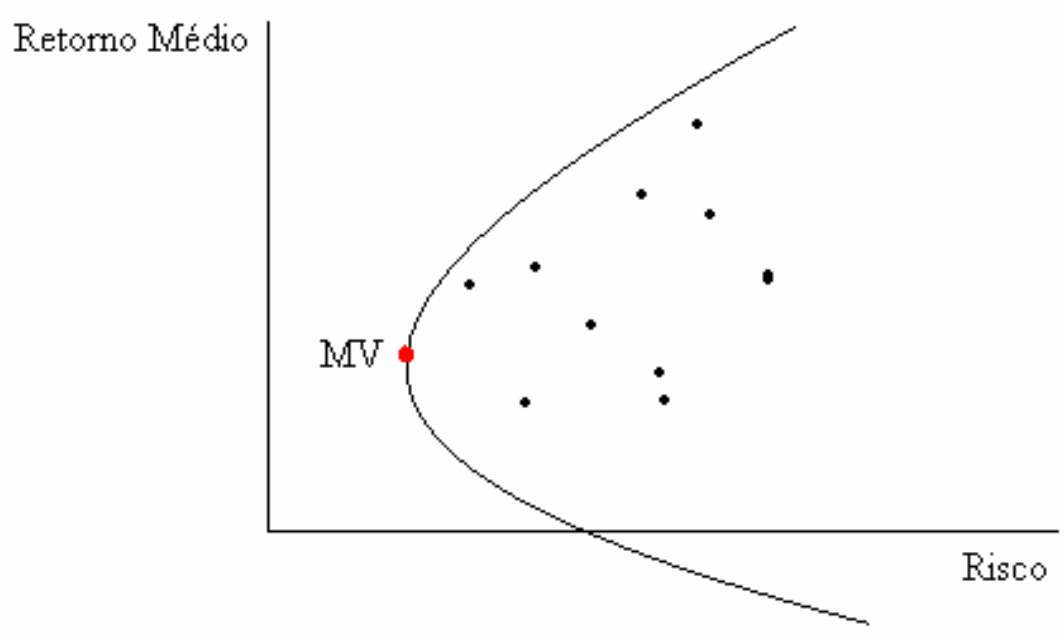

Figura 2. Fronteira eficiente.

Considerando as premissas de mercado eficiente, percebe-se que a curva da fronteira eficiente contém as carteiras com menor nível de risco e maior nível de retorno. O ponto MV (Mínima Variância) é a carteira com mais baixo nível de variância (ou risco).

Dentro desta curva pode-se encontrar diferentes perfis de risco - retorno e estes devem se adequar ao perfil do investidor. A curva representa as melhores carteiras para diferentes perfis de risco. Assim, uma vez estimados os parâmetros dos ativos, ou seja, os retornos, riscos (variâncias) e as covariâncias, podemos encontrar uma série de carteiras só alterando os valores das composições. É importante ressaltar dois aspectos: (a) a obtenção da fronteira eficiente de ativos de risco independe do tipo de investidor. Ela resulta tão somente da aplicação do Princípio de Dominância à relação retorno e risco, que por sua vez depende apenas dos ativos considerados; (b) a solução final, isto é, a carteira ótima, é que depende do comportamento do investidor. Ela é obtida varrendo a região factível (a fronteira eficiente de ativos de risco) com as curvas de utilidade particulares dos investidores. Essas premissas definidas para o modelo satisfazem aqueles investidores avessos ao risco, em que se maximiza a utilidade esperada dos retornos esperados pressupondo-se que os retornos dos títulos tenham uma distribuição normal. Apesar de gerar alguns desvios, estas premissas, na prática, são validadas e não chegam a prejudicar o modelo.

Posteriormente ao modelo de Markowitz (1952), Elton e Gruber (1995) desenvolveram outro procedimento para montagem de carteiras ótimas que, além de ter uma metodologia de cálculo simples, demonstra o porquê de uma ação pertencer a uma carteira ótima. O modelo proposto utiliza as seguintes variáveis para um determinado período de tempo: retorno esperado de cada ação $-\bar{R}_{i}$; beta de cada ação - $\beta_{i}$; retorno do título de renda fixa sem risco - $R_{F}$; risco diversificável de cada ação - $\sigma_{e i}$; risco da carteira de mercado $\sigma_{M}$.

A metodologia segue três fases. Inicialmente calcula-se o retorno esperado por ação em percentuais $\left(\bar{R}_{i}\right)$, seus respectivos retornos excessivos $\left(\bar{R}_{i}-R_{F}\right)$ também em percentuais, betas $\left(\beta_{i}\right)$ e o índice de atratividade $\left(\bar{R}_{i}-R_{F}\right) / \beta_{i}$, que nada mais é do que o retorno excessivo dividido pelo beta de cada ação. Nesta representação do Índice de Atratividade (IA), está implícito que o investidor não pode esperar ser remunerado no seu investimento por 
assumir o denominado risco diversificável $\left(\sigma_{e i}\right)$ isto porque esse risco poderá ser eliminado por um processo de diversificação eficiente. Portanto, o investidor só pode exigir uma remuneração adicional sobre a rentabilidade do título de renda fixa sem risco em virtude daquele risco que ele é sempre obrigado a correr (o risco não diversificável ou sistemático) se ele optar por investir em ativos com risco (de retorno incerto). Se as ações forem classificadas de acordo com esse IA, sua atratividade estará definida, uma vez que quanto maior esse índice para a ação maior a rentabilidade excedente esperada por unidade e risco sistemático. (TOSTA DE SÁ, 1999, p. 103).

Em seguida o modelo classifica, em ordem decrescente do índice de atratividade, todos os dados calculados anteriormente por ação. Logo após, calcula-se o ponto de corte $\left(\mathrm{C}^{*}\right)$ com o objetivo de selecionar as ações que vão compor a carteira ótima. As ações que possuírem Índices de Atratividades superiores aos pontos de corte comporão a carteira, ao contrário, deverão ser descartadas. Segundo Elton e Gruber (1995, p. 184), o valor do ponto de corte é computado a partir das características de todas as ações que pertencerão ao portfolio ótimo. Para determinar $C^{*}$ é necessário calcular seus valores como se houvesse diferentes números de ações no portfolio ótimo. Na última etapa do método, calcula-se o percentual dos recursos disponíveis que devem ser investidos em cada ação selecionada, anteriormente, do portfólio ótimo.

Nos mercados financeiros, a cotação das ações é fixada pelas decisões de compra e venda tomadas pelo conjunto dos investidores, as quais são tomadas em função das suas previsões. As previsões são complexas. Muitos motivos podem ser apresentados: o futuro das empresas cotadas é incerto; os investidores têm antecipações heterogêneas; as decisões são diferentes e muitas vezes pouco racionais; a informação não é necessariamente perfeita e instantânea; os impostos são diferentes consoante os agentes; e, existem custos de transação.

Os pressupostos gerais dos modelos de gestão financeira, considerando os mercados perfeitos são: trabalhar em concorrência perfeita; a informação é total e a sua utilização se processa em condições de igualdade e sem custos; todos os ativos são infinitamente divisíveis e perfeitamente negociáveis; não existem impostos nem custos de transação, como comissões e taxas bancárias; não existem limitações à obtenção de fundos; as expectativas dos investidores são homogêneas, ou seja, todas fazem as mesmas apreciações das rentabilidades futuras; todos os investidores são racionais: o seu objetivo consiste em maximizar a utilidade das suas riquezas; e, a racionalidade dos investidores exprime-se também pela homogeneidade das suas atitudes em relação ao risco. Na prática, a informação não é necessariamente perfeita já que existem custos de transação e impostos, os investidores têm antecipações heterogêneas, assim como preferências freqüentemente pouco racionais.

Apesar desses pressupostos e suas imperfeições mostrarem um conjunto de oportunidades de investimentos, as suposições a respeito das funções de preferências dos investidores, para limitar o conjunto de oportunidades, deve ser levada em conta. De acordo com Elton et. al. (2004), se o investidor preferir mais retorno e tiver avesso ao risco, o conjunto de oportunidades poderá ser reduzido à fronteira eficiente. Os autores também mencionaram que, se for possível aplicar ou captar sem risco a mesma taxa de juros em quantidades ilimitadas, então haverá uma única carteira de ativos com risco ideal para um investidor com aversão ao risco, independente da função de preferências do investidor. Qualquer que seja o conjunto de oportunidades para o investidor, sua função de preferências ainda desempenhará papel-chave na otimização de sua decisão. 
Diante disso, diversas informações sobre uma empresa ou ação deve ser levada em conta no processo decisório da montagem de carteiras de ações, com o intuito de se obter maiores retornos e menores riscos.

O modelo de análise de média-variância para a escolha da carteira ótima é a mais utilizada mas, outros métodos são utilizados objetivando otimizar o processo de administração de ativos. De acordo com Elton et. al. (2004), uma alternativa à análise média-variância consiste simplesmente na escolha da carteira que oferece o retorno médio geométrico mais elevado. Um segundo conjunto de alternativas à análise de média-variância, defendido na literatura, é a dominância estocástica. A forma mais geral de dominância estocástica não faz qualquer hipótese sobre a forma da distribuição de probabilidades dos retornos. O terceiro grupo de critérios alternativos ao teorema da média-variância, é o chamado "segurança em primeiro lugar". Esses modelos resultam da crença de que os responsáveis pela tomada de decisão não são capazes ou não se dispõem a fazer cálculos matemáticos exigidos pelo teorema da média-variância, também chamada de utilidade esperada, mas recorrem a um modelo decisório mais simples e que concentra a atenção em resultados desfavoráveis.

\section{METODOLOGIA}

As amostras de ações para formar as carteiras de Elton-Gruber tiveram como critério o índice de liquidez da Bolsa de Valores de São Paulo. Foram selecionadas as vinte primeiras ações com maiores índices de liquidez. A mesma amostra foi utilizada para verificação da eficiência informacional fraca do mercado de ações no Brasil. A coleta restringe-se ao período estudado necessário para montagem das carteiras e validações dos pressupostos que é de janeiro de 2000 a setembro de 2006. O critério de índice de liquidez foi utilizado com o objetivo de reduzir os problemas decorrentes da falta de negociabilidade de determinadas ações.

A medida de liquidez empregada foi o Índice de Negociabilidade em Bolsa (INB) descrito pela fórmula:

$$
I N B=100 \cdot \frac{p}{P} \sqrt{\frac{n}{N} \cdot \frac{v}{V}}
$$

Onde: $\mathrm{p}=$ número de dias em que houve pelo menos um negócio com a ação dentro do período escolhido; $\mathrm{P}=$ número total de dias do período escolhido; $\mathrm{n}=$ número de negócios com a ação dentro do período escolhido; $\mathrm{N}$ = número de negócios com todas as ações dentro do período escolhido; $\mathrm{v}=$ volume em dinheiro de negociações com a ação dentro do período escolhido; $\mathrm{V}=$ volume em dinheiro de negociações com todas as ações dentro do período escolhido. O período empregado para o cálculo do INB foi de 5 anos anteriores a janeiro de 2000, ou seja, foram utilizados dados desde janeiro de 1995.

A medida de Presença em Bolsa foi calculada através da fórmula:

$$
P B=100 \cdot \frac{p}{P}
$$

Onde: $\mathrm{p}=$ numero de dias em que houve pelo menos um negócio com a ação dentro do período escolhido; $\mathrm{P}=$ número total de dias do período escolhido.

As informações empregadas no presente estudo foram coletadas na base de dados da Economática. Com base nos dados coletados foram calculados o logaritmo neperiano dos retornos, sua média e desvio-padrão. Posteriormente, foram construídas simulações de carteiras utilizando o modelo de Elton-Gruber.

A validação das performances ocorreu mediante o uso dos seguintes indicadores: 
a) índices de Sharpe: índice que relaciona rentabilidade e risco (total). Ele é utilizado para a quantificação do desempenho de uma carteira de títulos (ex-post).

$$
I S=\frac{\bar{R}_{P}-R_{F}}{\sigma_{P}}
$$

Onde: $\bar{R}_{P}=$ retorno médio de uma carteira; $\sigma_{P}=$ desvio padrão dos retornos de uma carteira; $R_{F}=$ retorno de um ativo sem risco.

b) Índice de Treynor: É utilizado para a quantificação do desempenho de uma carteira de títulos (ex-post).

$$
I T=\frac{\bar{R}_{P}-R_{F}}{\beta_{P}}
$$

Onde: $\bar{R}_{P}=$ retorno médio de uma carteira; $R_{F}=$ retorno de um ativo sem risco; $\beta_{P}$ $=$ beta da carteira.

Os procedimentos de otimização de carteiras com base no modelo de Elton-Gruber empregaram o índice da Bolsa de Valores de São Paulo, o Ibovespa, como parâmetro de retorno de mercado e a taxa Selic como parâmetro de taxa livre de risco.

\section{RESULTADOS OBTIDOS}

$\mathrm{O}$ resumo dos resultados das rentabilidades auferidas com as carteiras elaboradas pelo método de Elton-Gruber no período de 2001 a 2006 está apresentado na Tabela 1. O portfólio otimizado está sendo comparado à carteira de mercado, representada pelo Ibovespa, e pela taxa livre de risco, representada pela taxa Selic. 
Tabela 1. Resumo dos resultados.

\begin{tabular}{|c|c|c|c|c|c|c|}
\hline \multirow[b]{2}{*}{ MÊS } & \multicolumn{2}{|c|}{ Critério Elton-Gruber } & \multicolumn{2}{|c|}{ IBOVESPA } & \multicolumn{2}{|c|}{ Tx Selic Efetiva Mes (Rf) } \\
\hline & Retorno médio & $\begin{array}{c}\text { Retorno } \\
\text { acumulado }\end{array}$ & Retorno médio & $\begin{array}{c}\text { Retorno } \\
\text { acumulado }\end{array}$ & Retorno médio & $\begin{array}{c}\text { Retorno } \\
\text { acumulado }\end{array}$ \\
\hline $\mathrm{jan} / 01$ & $15,38 \%$ & $15,38 \%$ & $14,68 \%$ & $14,68 \%$ & $1,26 \%$ & $1,26 \%$ \\
\hline $\mathrm{fev} / 01$ & $-11,60 \%$ & $3,79 \%$ & $-10,62 \%$ & $4,06 \%$ & $1,02 \%$ & $2,28 \%$ \\
\hline $\operatorname{mar} / 01$ & $1,05 \%$ & $4,84 \%$ & $-9,59 \%$ & $-5,53 \%$ & $1,26 \%$ & $3,54 \%$ \\
\hline $\mathrm{abr} / 01$ & $6,39 \%$ & $11,23 \%$ & $3,26 \%$ & $-2,27 \%$ & $1,19 \%$ & $4,72 \%$ \\
\hline mai/01 & $-0,93 \%$ & $10,29 \%$ & $-1,81 \%$ & $-4,08 \%$ & $1,34 \%$ & $6,06 \%$ \\
\hline jun/01 & $1,06 \%$ & $11,35 \%$ & $-0,62 \%$ & $-4,70 \%$ & $1,27 \%$ & $7,33 \%$ \\
\hline $\mathrm{jul} / 01$ & $-7,32 \%$ & $4,04 \%$ & $-5,69 \%$ & $-10,38 \%$ & $1,44 \%$ & $8,77 \%$ \\
\hline ago/01 & $-2,77 \%$ & $1,26 \%$ & $-6,88 \%$ & $-17,26 \%$ & $1,60 \%$ & $10,37 \%$ \\
\hline set/01 & $-11,50 \%$ & $-10,24 \%$ & $-18,84 \%$ & $-36,10 \%$ & $1,32 \%$ & $11,69 \%$ \\
\hline out $/ 01$ & $2,09 \%$ & $-8,15 \%$ & $6,63 \%$ & $-29,47 \%$ & $1,53 \%$ & $13,23 \%$ \\
\hline nov/01 & $8,92 \%$ & $0,77 \%$ & $12,92 \%$ & $-16,55 \%$ & $1,39 \%$ & $14,62 \%$ \\
\hline $\mathrm{dez} / 01$ & $0,47 \%$ & $1,24 \%$ & $4,87 \%$ & $-11,68 \%$ & $1,39 \%$ & $16,02 \%$ \\
\hline $\mathrm{jan} / 02$ & $1,60 \%$ & $2,84 \%$ & $-6,51 \%$ & $-18,19 \%$ & $1,53 \%$ & $17,55 \%$ \\
\hline $\mathrm{fev} / 02$ & $3,57 \%$ & $6,41 \%$ & $9,82 \%$ & $-8,38 \%$ & $1,25 \%$ & $18,79 \%$ \\
\hline $\mathrm{mar} / 02$ & $-0,94 \%$ & $5,47 \%$ & $-5,71 \%$ & $-14,09 \%$ & $1,37 \%$ & $20,17 \%$ \\
\hline $\mathrm{abr} / 02$ & $1,22 \%$ & $6,69 \%$ & $-1,28 \%$ & $-15,37 \%$ & $1,48 \%$ & $21,65 \%$ \\
\hline $\mathrm{mai} / 02$ & $-1,31 \%$ & $5,38 \%$ & $-1,73 \%$ & $-17,10 \%$ & $1,41 \%$ & $23,06 \%$ \\
\hline jun/02 & $-2,15 \%$ & $3,23 \%$ & $-14,37 \%$ & $-31,47 \%$ & $1,33 \%$ & $24,39 \%$ \\
\hline $\mathrm{jul} / 02$ & $1,22 \%$ & $4,45 \%$ & $-13,20 \%$ & $-44,67 \%$ & $1,54 \%$ & $25,93 \%$ \\
\hline ago/02 & $-2,73 \%$ & $1,71 \%$ & $6,16 \%$ & $-38,51 \%$ & $1,44 \%$ & $27,37 \%$ \\
\hline set/02 & $-5,85 \%$ & $-4,13 \%$ & $-18,58 \%$ & $-57,09 \%$ & $1,38 \%$ & $28,75 \%$ \\
\hline out/02 & $31,43 \%$ & $27,30 \%$ & $16,48 \%$ & $-40,60 \%$ & $1,65 \%$ & $30,40 \%$ \\
\hline nov/02 & $13,83 \%$ & $41,13 \%$ & $3,30 \%$ & $-37,30 \%$ & $1,54 \%$ & $31,94 \%$ \\
\hline $\mathrm{dez} / 02$ & $29,75 \%$ & $70,88 \%$ & $6,98 \%$ & $-30,32 \%$ & $1,74 \%$ & $33,68 \%$ \\
\hline jan/03 & $9,95 \%$ & $80,83 \%$ & $-2,94 \%$ & $-33,27 \%$ & $1,97 \%$ & $35,65 \%$ \\
\hline $\mathrm{fev} / 03$ & $-31,26 \%$ & $49,57 \%$ & $-6,23 \%$ & $-39,50 \%$ & $1,83 \%$ & $37,48 \%$ \\
\hline $\mathrm{mar} / 03$ & $20,13 \%$ & $69,71 \%$ & $9,22 \%$ & $-30,28 \%$ & $1,78 \%$ & $39,26 \%$ \\
\hline $\mathrm{abr} / 03$ & $28,03 \%$ & $97,74 \%$ & $10,78 \%$ & $-19,50 \%$ & $1,87 \%$ & $41,13 \%$ \\
\hline mai/03 & $6,05 \%$ & $103,79 \%$ & $6,66 \%$ & $-12,83 \%$ & $1,97 \%$ & $43,09 \%$ \\
\hline jun/03 & $4,50 \%$ & $108,29 \%$ & $-3,40 \%$ & $-16,24 \%$ & $1,86 \%$ & $44,95 \%$ \\
\hline $\mathrm{jul} / 03$ & $15,34 \%$ & $123,63 \%$ & $4,51 \%$ & $-11,72 \%$ & $2,08 \%$ & $47,04 \%$ \\
\hline $\mathrm{ago} / 03$ & $-1,69 \%$ & $121,94 \%$ & $11,16 \%$ & $-0,56 \%$ & $1,77 \%$ & $48,81 \%$ \\
\hline set/03 & $-3,02 \%$ & $118,91 \%$ & $5,36 \%$ & $4,80 \%$ & $1,68 \%$ & $50,49 \%$ \\
\hline out $/ 03$ & $-1,32 \%$ & $117,59 \%$ & $11,62 \%$ & $16,42 \%$ & $1,64 \%$ & $52,13 \%$ \\
\hline nov/03 & $-2,25 \%$ & $115,34 \%$ & $11,55 \%$ & $27,97 \%$ & $1,34 \%$ & $53,47 \%$ \\
\hline $\mathrm{dez} / 03$ & $2,25 \%$ & $117,59 \%$ & $9,69 \%$ & $37,65 \%$ & $1,37 \%$ & $54,85 \%$ \\
\hline
\end{tabular}


Continuação.

\begin{tabular}{|c|c|c|c|c|c|c|}
\hline \multirow[b]{2}{*}{ MÊES } & \multicolumn{2}{|c|}{ Critério Elton-Gruber } & \multicolumn{2}{|c|}{ IBOVESPA } & \multicolumn{2}{|c|}{ Tx Selic Efetiva Mes (Rf) } \\
\hline & Retorno médio & $\begin{array}{c}\text { Retorno } \\
\text { acumulado }\end{array}$ & Retorno médio & $\begin{array}{c}\text { Retorno } \\
\text { acumulado }\end{array}$ & Retorno médio & $\begin{array}{c}\text { Retorno } \\
\text { acumulado }\end{array}$ \\
\hline $\mathrm{jan} / 04$ & $-6,8 \%$ & $110,79 \%$ & $-1,75 \%$ & $35,91 \%$ & $1,27 \%$ & $56,12 \%$ \\
\hline $\mathrm{fev} / 04$ & $9,2 \%$ & $119,99 \%$ & $-0,44 \%$ & $35,47 \%$ & $1,08 \%$ & $57,20 \%$ \\
\hline $\operatorname{mar} / 04$ & $11,4 \%$ & $131,37 \%$ & $1,76 \%$ & $37,23 \%$ & $1,38 \%$ & $58,58 \%$ \\
\hline $\mathrm{abr} / 04$ & $-27,1 \%$ & $104,25 \%$ & $-12,16 \%$ & $25,07 \%$ & $1,18 \%$ & $59,76 \%$ \\
\hline mai/04 & $1,2 \%$ & $105,42 \%$ & $-0,32 \%$ & $24,75 \%$ & $1,23 \%$ & $60,99 \%$ \\
\hline jun $/ 04$ & $7,5 \%$ & $112,93 \%$ & $7,89 \%$ & $32,64 \%$ & $1,23 \%$ & $62,22 \%$ \\
\hline $\mathrm{jul} / 04$ & $22,1 \%$ & $135,03 \%$ & $5,47 \%$ & $38,10 \%$ & $1,29 \%$ & $63,51 \%$ \\
\hline ago/04 & $6,3 \%$ & $141,30 \%$ & $2,07 \%$ & $40,17 \%$ & $1,29 \%$ & $64,80 \%$ \\
\hline set/04 & $-3,5 \%$ & $137,81 \%$ & $1,92 \%$ & $42,09 \%$ & $1,25 \%$ & $66,05 \%$ \\
\hline out $/ 04$ & $-4,6 \%$ & $133,20 \%$ & $-0,83 \%$ & $41,26 \%$ & $1,21 \%$ & $67,26 \%$ \\
\hline nov/04 & $23,1 \%$ & $156,30 \%$ & $8,62 \%$ & $49,88 \%$ & $1,25 \%$ & $68,51 \%$ \\
\hline $\mathrm{dez} / 04$ & $-0,3 \%$ & $156,03 \%$ & $4,16 \%$ & $54,04 \%$ & $1,48 \%$ & $70,00 \%$ \\
\hline jan/05 & $-3,9 \%$ & $152,13 \%$ & $-7,31 \%$ & $46,74 \%$ & $1,38 \%$ & $71,38 \%$ \\
\hline $\mathrm{fev} / 05$ & $14,4 \%$ & $166,53 \%$ & $14,46 \%$ & $61,20 \%$ & $1,22 \%$ & $72,60 \%$ \\
\hline $\mathrm{mar} / 05$ & $-7,1 \%$ & $159,40 \%$ & $-5,59 \%$ & $55,61 \%$ & $1,53 \%$ & $74,13 \%$ \\
\hline $\mathrm{abr} / 05$ & $-12,9 \%$ & $146,52 \%$ & $-6,87 \%$ & $48,74 \%$ & $1,41 \%$ & $75,54 \%$ \\
\hline $\mathrm{mai} / 05$ & $-6,0 \%$ & $140,57 \%$ & $1,45 \%$ & $50,20 \%$ & $1,50 \%$ & $77,04 \%$ \\
\hline jun $/ 05$ & $-10,4 \%$ & $130,18 \%$ & $-0,62 \%$ & $49,57 \%$ & $1,59 \%$ & $78,63 \%$ \\
\hline $\mathrm{jul} / 05$ & $-1,6 \%$ & $128,59 \%$ & $3,88 \%$ & $53,45 \%$ & $1,51 \%$ & $80,14 \%$ \\
\hline ago/05 & $14,7 \%$ & $143,33 \%$ & $7,41 \%$ & $60,86 \%$ & $1,66 \%$ & $81,80 \%$ \\
\hline set/05 & $4,1 \%$ & $147,46 \%$ & $11,88 \%$ & $72,74 \%$ & $1,50 \%$ & $83,30 \%$ \\
\hline out $/ 05$ & $-11,8 \%$ & $135,66 \%$ & $-4,50 \%$ & $68,24 \%$ & $1,41 \%$ & $84,71 \%$ \\
\hline nov/05 & $3,7 \%$ & $139,39 \%$ & $5,55 \%$ & $73,79 \%$ & $1,38 \%$ & $86,09 \%$ \\
\hline $\mathrm{dez} / 05$ & $2,2 \%$ & $141,62 \%$ & $4,71 \%$ & $78,50 \%$ & $1,47 \%$ & $87,56 \%$ \\
\hline jan/06 & $20,4 \%$ & $161,98 \%$ & $13,74 \%$ & $92,24 \%$ & $1,43 \%$ & $88,99 \%$ \\
\hline $\mathrm{fev} / 06$ & $3,3 \%$ & $165,31 \%$ & $0,59 \%$ & $92,83 \%$ & $1,15 \%$ & $90,14 \%$ \\
\hline $\mathrm{mar} / 06$ & $-4,4 \%$ & $160,93 \%$ & $-1,72 \%$ & $91,11 \%$ & $1,42 \%$ & $91,56 \%$ \\
\hline $\mathrm{abr} / 06$ & $3,3 \%$ & $164,20 \%$ & $6,16 \%$ & $97,27 \%$ & $1,08 \%$ & $92,64 \%$ \\
\hline $\mathrm{mai} / 06$ & $-11,1 \%$ & $153,14 \%$ & $-9,98 \%$ & $87,30 \%$ & $1,28 \%$ & $93,92 \%$ \\
\hline jun/06 & $-0,5 \%$ & $152,67 \%$ & $0,27 \%$ & $87,57 \%$ & $1,18 \%$ & $95,10 \%$ \\
\hline $\mathrm{jul} / 06$ & $5,6 \%$ & $158,29 \%$ & $1,21 \%$ & $88,78 \%$ & $1,17 \%$ & $96,27 \%$ \\
\hline ago/06 & $-0,2 \%$ & $158,09 \%$ & $-2,31 \%$ & $86,48 \%$ & $1,26 \%$ & $97,53 \%$ \\
\hline set/06 & $2,1 \%$ & $160,18 \%$ & $0,60 \%$ & $87,07 \%$ & $1,06 \%$ & $98,59 \%$ \\
\hline MÉDIA & $2,3 \%$ & & $1,3 \%$ & & $1,4 \%$ & \\
\hline D.Padrão & $11,3 \%$ & & $8,0 \%$ & & $0,2 \%$ & \\
\hline Variância & $1,3 \%$ & & $0,6 \%$ & & $0,0 \%$ & \\
\hline I.Treynor & 0,01 & & $(0,00)$ & & & \\
\hline I.Sharpe & 0,08 & & $(0,02)$ & & & \\
\hline
\end{tabular}

A metodologia proposta pelo modelo Elton-Gruber apresentou o maior retorno médio no período igual a 2,3\% a. m. O Ibovespa obteve um retorno médio mensal igual a $1,3 \%$ e, a taxa Selic apresentou $1,4 \%$ de retorno médio no mesmo período. Analisando o retorno acumulado, a carteira de Elton-Gruber obteve 160,2\%, seguido da taxa Selic com 98,6\% e do Ibovespa $87,1 \%$. O risco médio representado pelo desvio-padrão tem como maior valor o da própria carteira otimizada com $11,3 \%$. O Ibovespa possui $8,0 \%$ de desvio padrão e a Selic $0,2 \%$. 
Para avaliar o desempenho das carteiras foram utilizados os índices de Sharpe e Treynor. O índice de Sharpe relaciona a rentabilidade e o risco (total), ou seja, ele expressa a rentabilidade média excedente por unidade de risco total da carteira. Entende-se por rentabilidade média excedente a diferença entre a rentabilidade média da carteira no período em análise e a rentabilidade certa do ativo sem risco.

Como a rentabilidade do ativo sem risco não se manteve constante ao longo dos vários subperíodos que compõem o período total em análise, foi realizada a seguinte adaptação para a fórmula do índice de Sharpe:

$$
I S=\frac{\bar{R}_{P}-R_{F}}{\sigma_{P}-\sigma_{F}}
$$

Onde: $\sigma_{F}=$ desvio-padrão dos retornos do ativo livre de risco. Obteve-se um índice de Sharpe igual a 0,08 para carteira de Elton-Gruber (melhor desempenho) e -0,02 para o Ibovespa. Apesar de haver controvérsias sobre resultados negativos do índice de Sharpe, no período analisado o desempenho do Ibovespa foi negativo porque os resultados do titulo de Renda Fixa foram superiores ao Ibovespa.

O índice de Treynor, que é uma medida de excesso de retorno em relação ao beta, também exibiu desempenho superior para as carteiras de Elton-Gruber com 0,01, enquanto a carteira de mercado obteve 0,00 .

Objetivando analisar o quanto significantes são as diferenças entre os retornos das carteiras de ações e índices, os testes não-paramétricos Kruskal-Wallis e Mood foram executados. Estes testes foram selecionados em detrimento do One-way Anova devido ao fato dos testes de normalidade Kolmogorov-Smirnov e Anderson-Darling terem apresentado pvalues menores que o nível de significância $(\alpha)$ de $5 \%$ para os retornos das carteiras de EltonGruber e para o Ibovespa indicando não normalidade dos dados. A Tabela 2 exibe o resumo dos resultados obtidos dos testes Kolmogorov-Smirnov e Anderson-Darling.

Tabela 2. Resultados dos testes de normalidade.

\begin{tabular}{lrr}
\hline \multicolumn{1}{c}{ Teste normalidade } & $\begin{array}{c}\text { Carteira Elton- } \\
\text { Gruber }\end{array}$ & Ibovespa \\
\hline $\mathrm{N}$ & 69 & 69 \\
Média & 89,17 & 20,83 \\
Desvio padrão & 63,41 & 43,55 \\
Kolmogorov-Smirnov (P-Value) & $<0,010$ & 0,01 \\
Anderson-Darling (P-Value) & $<0,005$ & $<0,005$ \\
\hline
\end{tabular}

Os testes não paramétricos de Kruskal-Wallis para igualdade de medianas foram executados, estando apresentados na Tabela 3.

Tabela 3. Resultados dos testes de igualdade de mediana dos retornos das carteiras de ações de Elton-Gruber e do Ibovespa 


\begin{tabular}{llrrc}
\hline \multicolumn{5}{c}{ Kruskal-Wallis Test: Retorno acumulado } \\
\hline \multicolumn{1}{c}{ Carteira } & $\mathrm{N}$ & Mediana & Ave Rank & $\mathrm{Z}$ \\
\hline $\mathrm{EG}$ & 69 & 115,34 & 90,60 & 6,2 \\
Ibovespa & 69 & 24,75 & 48,40 & $-6,2$ \\
\hline $\mathrm{H}=38,47$ & $\mathrm{DF}=1$ & $\mathrm{P}=0,000$ & & Resultado: significante \\
\hline
\end{tabular}

Os resultados do teste Kruskal-Wallis expostos na Tabela 3 permitem concluir que, ao nível de significância de 5\%, há evidência suficiente para rejeitar a hipótese nula para igualdade das medianas dos retornos, ou seja, pode-se afirmar que existe diferença entre os retornos das carteiras otimizadas sob o método de Elton-Gruber e o Ibovespa. O teste para igualdade de medianas de Mood também foi executado e seus resultados estão apresentados na Tabela 4.

Tabela 4. Teste de igualdade de mediana dos retornos das carteiras de ações de Elton-Gruber e do Ibovespa Mood Test

\begin{tabular}{lccrr}
\hline \multicolumn{5}{c}{ Mood Median Test: Retorno acumulado } \\
\hline \multicolumn{1}{c}{ Carteira } & $\mathrm{N}<=$ & $\mathrm{N}>$ & Mediana & $Q 3-Q 1$ \\
\hline EG & 23 & 46 & 115 & 134 \\
Ibovespa & 46 & 23 & 25 & 70 \\
\hline Chi-Square $=15,33$ & $\mathrm{DF}=1$ & $\mathrm{P}=0,000$ & & \\
\hline 95\% Intervalo de Confiança & & Resultado: significante \\
\hline
\end{tabular}

De forma similar ao resultado do teste Kruskal-Wallis, o teste de Mood revela um valor de Qui-quadrado de 15,33 com um nível de significância igual a 0,000, indicando que há evidência suficiente para rejeitar a hipótese nula em favor da hipótese alternativa. Ambos os testes revelaram significância estatística para a diferença entre as populações dos retornos das carteiras formadas pelo método de Elton-Gruber e a carteira do mercado de ações brasileiro, o Ibovespa, indicando que há vantagens na utilização do método sugerido sobre a simples utilização do índice de mercado. Estes resultados validam a hipótese alternativa do estudo, sobre a existência de desempenhos superiores de carteiras de ações com a aplicação do método de Elton-Gruber no Brasil no período de janeiro de 2000 a setembro de 2006.

\section{CONSIDERAÇÕES FINAIS}

O objetivo principal do trabalho buscou analisar a possibilidade de encontrar desempenhos superiores nas estratégias de investimentos mediante o emprego da técnica de formação de carteira de ações com base no método de Elton-Gruber no período de 2000 a setembro de 2006 em relação ao Ibovespa. Para isso foram utilizadas as mesmas vinte ações mais líquidas da Bovespa. Executou-se o procedimento de montagem de carteiras de EltonGruber e seus desempenhos foram comparados aos do índice da Bovespa, o Ibovespa. O modelo de Elton-Gruber apresentado mostrou-se eficaz para formação de portfólio ótimo quando superou a carteira de mercado em diversos aspectos. A carteira de EG obteve retorno acumulado no período de $160,18 \%$, o Ibovespa conseguiu $87,07 \%$ e a taxa livre de risco considerada neste trabalho, a Selic, atingiu 98,59\% de retorno. A metodologia de EltonGruber apresentou o maior retorno médio no período com $2,3 \%$. A carteira que representa o mercado brasileiro obteve um retorno médio $1,3 \%$ e, a taxa Selic, auferiu $1,4 \%$ de retorno médio no mesmo período. O risco médio representado pelo desvio-padrão tem como líder a própria carteira otimizada com $11,3 \%$. O Ibovespa possui $8,0 \%$ de desvio padrão e a Selic $0,2 \%$. 
Para avaliar o desempenho das carteiras foram utilizados os índices de Sharpe e Treynor. O índice de Sharpe da carteira de Elton-Gruber foi de 0,08 (melhor desempenho) e o Ibovespa -0,02. O desempenho do Ibovespa foi negativo porque os retornos do título de Renda Fixa foram superiores ao do Ibovespa. O índice de Treynor, também exibiu desempenho superior para as carteiras de Elton-Gruber com 0,01 , enquanto a carteira de mercado obteve 0,00 .

Objetivando analisar o quanto significantes foram as diferenças entre os retornos das carteiras de ações e do índice, os testes não-paramétricos Kruskal-Wallis e Mood foram executados. Considerando-se o nível de significância de $5 \%$, ambos os testes chegaram à mesma conclusão de que há evidência suficiente para rejeitar a hipótese nula de igualdade das medianas dos retornos em favor da hipótese alternativa, indicando que há vantagens na utilização do método sugerido de Elton-Gruber sobre a simples utilização do índice de mercado, o Ibovespa.

Devido à sua simplicidade comparada a outros métodos, o modelo de Elton-Gruber se apresenta como uma ferramenta a ser considerada para investidores e administradores de carteira de ações, tendo em vista que indica as razões que levam um determinado ativo a pertencer ou não a uma carteira ótima. A aplicação dos procedimentos sugeridos pode proporcionar retornos maiores que aplicações baseadas em índices de bolsa, com menores riscos.

\section{REFERENCIAS}

ASSAF NETO, Alexandre. Mercado Financeiro. São Paulo: Atlas, 2001.

ELTON, Edwin J.; GRUBER, Martin J., Modern Portfolio Theory and Investment Analysis, 5th ed. New York: John Wiley \& Sons, Inc, 1995.

ELTON, Edwin J. et al. Moderna teoria de carteiras e análise de investimentos. São Paulo: Atlas, 2004.

MARKOWITZ, Harry. Portfolio Selection. The journal of finance. Vol. 7, nº 1, p. 77-91, Mar. 1952.

TOSTA DE SÁ, Geraldo. Administração de Investimentos: Teoria de Carteiras e Gerenciamento do Risco. Rio de Janeiro: Qualitymark Ed., 1999. 376 p. 